\title{
Every Teacher is a Language Teacher \\ Preparing teacher candidates for English language learners through service-learning
}

\section{Yanan Fan}

San Francisco State University

Gateways: International Journal of Community Research and Engagement Vol 6 (2013): 77-92

(C) UTSePress and the author

ISSN 1836-3393
Secondary school teachers in the United States are facing urgent challenges in their increasingly heterogeneous classrooms where the presence of English language learners (ELLs) is becoming the norm. ELLs tend to be much more disadvantaged than their English-proficient peers in terms of socioeconomic resources and academic ability, and thus rely more on teachers to guide them through the precarious journey of surviving secondary school (Fan 2009). Research reveals that integrating language teaching in content teaching creates the best learning environments for secondary age ELLs to develop their academic language skills (Valdés 2001). Classroom teachers are therefore crucial facilitators of ELL student learning. (In this article, classroom teachers refer to mainstream, general education, content area, non-specialist teachers in secondary schools. They are not English as a Second Language (ESL), English Language Development (ELD), or bilingual education teachers.)

Given the urgency of preparing classroom teachers to serve ELLs, however, relatively few studies address the actual practice of integrating linguistic knowledge and language-related experience into teacher education. Only 20 states in the USA mandate ELLrelated training, and less than a sixth of teacher education programs nationwide offer such training to pre-service teachers (Ballantyne, Sanderman \& Levy 2008). Teacher education needs to fill this critical gap by offering 'a situated preparation within ELL communities that fosters the development of teacher knowledge of the dynamics of language in children's lives and communities' (García et al. 2010, p. 132). Lucas and Grinberg (2008) put forward a language-specific knowledge base for regular classroom teachers, and yet little research discusses ways to promote this knowledge base in teacher education programs.

Situating language teacher education in community-based service-learning has been widely practised, and for this case, in particular, it allows pre-service teachers to work with youth and adults from local, diverse and low socioeconomic neighbourhoods in the process of learning English. Researchers and practitioners (for example, Henry \& Breyfogle 2006) are paying special attention 
to the structure and pedagogy of service-learning in order to avoid the charity model of haves transmitting resources and knowledge to have-nots. In other words, service-learning should be a reciprocal experience in which 'everyone is in service and everyone can learn' (Stanton \& Erasmus 2013, p. 64). Fundamental understanding in service-learning requires that ' $[\mathrm{t}]$ he service must be relevant to the community and the content of the academic course, meaningful to the community and to the students, and developed and formulated with the community' (Howard 2001, p. 23).

Most recent studies of service-learning to prepare teacher candidates for working with ELLs investigate and conceptualise the impact of service-learning programs on participating teacher candidates (for example, Hale 2008; Spencer, Cox-Petersen \& Crawford 2005) and analyse specific pedagogy that is implemented in service-learning practice. For instance, based on qualitative data collected from 106 pre-service teachers (including 15 secondary candidates), Wong (2008) studied the nature of tutortutee relationships among pre-service teachers who participated in a service-learning college course and their English language students. Wong argues that stronger awareness of the political, social and cultural contexts of working with ELLs and development of culturally responsive pedagogy and disposition are key to preparing future teachers. Blum and de la Piedra (2010) report their use of counter-storytelling in two service-learning projects that led to candidates' critical examination of their assumptions about serving immigrant students. Similarly, Hallman \& Burdick (2011) investigated how secondary English language arts teachers could benefit from service-learning experience while developing an identity that connected to their content pedagogical skills.

While service-learning is viewed as an effective pedagogical practice that promotes empathy among teacher candidates towards under-represented children, and increases awareness of social justice, equity, civic engagement and work ethics (Hollins \& Guzman 2005), it is important to note that multiple-subject preservice teachers and elementary school children have been studied (for example, Hadjioannou \& Hutchinson 2010; Hart \& King 2007; Ponder, Veldt \& Lewis-Ferrell 2011; Szente 2008) far more than their single-subject counterparts. In addition, a specific focus is missing on developing secondary school teacher candidates' linguistic knowledge and language teaching while they are participating in ELL communities through service-learning projects (Friedman 2002).

In short, this article aims to address two intertwining needs in research - the need for teacher education to build candidates' linguistic knowledge and competence in a 'situated preparation[s] within English learner communities that fosters the development of teacher knowledge of the dynamics of language in children's lives and communities' (García et al. 2010, p. 132), and the need for community and university partners in service-learning to create 
'enriched form[s] of reciprocity' (Henry \& Breyfogle 2006, p. 29) in which all parties own their projects by sharing a collective goal and contributing to/benefiting from the experience.

Using the case study of a service-learning project, the article describes and analyses language learning and teaching experiences among a group of teacher candidates as they tutored ELLs in Northern California during Spring 2010. As a teacher educator and a researcher, I explore the result of incorporating a service-learning component in a single credential course on second language development. Research questions were: What linguistic knowledge and language-related experiences (Lucas \& Grinberg 2008) did candidates learn to build? How did they interact with local communities of ELLs and teachers? The following sections first introduce the service-learning project, and then discuss the linguistic, social and cultural knowledge the candidates gained and the mutual learning experiences within the local communities. The last section focuses on several implications of the study.

\section{THE SERVICE-LEARNING TUTEE PROJECT}

The study took place during a single-subject credential course on second language development (SLD) at a California state university in spring 2010. SLD examines the nature of first and second language acquisition and sheltered instruction in order to prepare candidates to address issues related to ELLs in mainstream classrooms. Candidates who earn a credential from this SB2042 (a California state mandate) compliant program are authorised to teach ELLs in public schools. The three-credit-bearing SLD is therefore a gate-keeping course.

As an instructor of SLD for several years, I initiated the service-learning component to address a persistent problem: a missing sense of contexts in instruction that may have led to a lack of connectedness and rigour in candidates' reflection on their knowledge and experience of working with ELLs. The new servicelearning component would enable candidates to observe and study closely with ELLs in real-life contexts (for example, workplace literacy and citizenship education). The move toward communitybased practices was grounded in a sociocultural perspective that views learning to teach as a situated social practice in which every member of a community plays an active role in constructing the experience (Lave \& Wenger 1991). The goal was to create learning environments that were culturally and linguistically meaningful for teacher candidates, in order to understand the social contexts of the lives of the immigrant youths and adults.

The service-learning component of SLD, a tutee project, was established after frequent and thorough communication between the author/instructor and the participating immigrant agencies throughout 2010 Fall Semester. Prior professional connections to the San Francisco Bay Area immigrant communities through field supervision, as well as support from the university's community 
liaison, the Institute for Civic and Community Engagement, played a vital role in laying the groundwork. With a collective goal of supporting the ELLs, the project, on the one hand, offered academic content and logistics to candidates. On the other hand, it enabled the immigrant agencies to share responsibilities through on-site supervision of candidates, modelling effective practices, co-teaching with both the instructor and the candidates, and assessing candidate performance over time. In short, the project was built upon mutual need and effective communication between the instructor and the community.

The tutee project involved 20 hours of service-learning work at an immigrant agency. During the 16-week coursework back on campus, discussion topics were tied to service-learning fieldwork to monitor and facilitate the process. For example, during the first two weeks when candidates chose organisations for their fieldwork, class readings and discussions laid out national debates and language policies for ELLs to help candidates contextualise their service in a broader social environment. In return, candidates documented the history and community information pertinent to their organisations in order to understand the immigrant populations they served. SLD also covered topics such as second language acquisition, academic language, teaching strategies and action/case studies, which guided candidate fieldwork and reflection. Candidates were evaluated through participation in discussion, four field reports documenting various aspects of their fieldwork, a final report on the service-learning experience and a formal presentation to class members. Quantitative and qualitative feedback from all participating agencies was also counted as part of candidates' participation and professionalism grade.

\section{Participants}

Twenty-eight single-subject credential candidates enrolled in the single-subject credential course and all voluntarily participated in this study in Spring 2010 when the service-learning SLD was first offered. Among the 28 candidates, there were 16 males and 12 females, mostly in their thirties. Furthermore, 18 candidates identified themselves as monolingual, 7 as bilingual and 3 as multilingual. Their subject breakdown was as follows: English, 6; Social Studies, 8; Science, 6; Arts, 2; Music, 2; Physical Education, 2; Mathematics, 1; and Foreign Language, 1. Twenty-one candidates reported that service-learning was a new concept to them, and 19 reported minimum experience teaching or assisting ELLs. Still, in a pre-project survey, many candidates stated that they valued a connection to the community and expected to learn more about language teaching from their ELLs and the project. As one wrote, service-learning 'broadens perspectives, provides philanthropic kickback, and betters the community'. Another candidate wrote, 'Just as I think it's important for my students to enter into the world, I value it for educators in the making' (preproject survey data). At the same time, some candidates voiced concerns about the practicality issues and the unknowns: 'It 
sounds important but I really don't know'; 'Important, yes; but I also think it can be more beneficial if done during 1st semester when the workload is smaller' (pre-project survey data).

In undertaking service-learning at 11 local agencies, the 28 candidates worked with ELLs, from teens to seniors, with varied literacy levels and educational and immigrant backgrounds. Based on the needs of different groups (for example, learning academic English in public schools, preparing for the workforce, applying for citizenship, or developing basic literacy skills), candidates were assigned various instructional roles, such as assisting site ESL teachers or leading small groups in adult education programs, tutoring in particular subject areas in after-school programs or teaching spoken English. Some candidates followed a curriculum in the more structured programs, while planning for others was more flexibly based on students' daily needs. Although few candidates had a chance to practise teaching in their subject area, they all experienced the challenge of teaching English exclusively to ELLs, which was the goal of the service-learning course.

\section{METHODS}

\section{Course Outline and Data Sources}

Data sources included pre- and post-project surveys, candidates' tutoring field reports, researcher field notes of classroom discussions, candidates' final project reports and presentation materials, candidates' mid-term and final evaluation of their learning and their progress with their tutees, and community organisation evaluation and feedback at the end of project. During the first week, a pre-project survey was administered to retrieve basic information about candidate demographics, their previous service-learning experiences and their expectations of the tutee project. At week 16, the last week of the semester, candidates completed a post-project survey to report their overall growth, struggles, and reassessment of their expectations of the tutee project, as well as their suggestions for project revision. The surveys documented candidates' reflections on their academic development as teachers and learners and their disposition in serving diverse student populations over time.

Candidates wrote four field reports over a 12-week span as they fulfilled their service-learning hours at their respective organisations. Each field report was approximately 700-1000 words in length. Prompt questions were provided to candidates suggesting possible areas for observation, inquiry and reflection. In Field Report 1, candidates documented the geographic, demographic and programmatic aspects of the organisation as well as the community and ELL population that the organisation served. Field Reports 2 and 3 focused on candidates' developing strategies in assisting ELLs and analyses of how English was negotiated among members of their learning communities, including the candidates themselves. Field Report 4 highlighted compelling teaching and/or learning moments and their impact 
on candidates' growth. All four field reports required candidates to connect their prior knowledge, observations and practice to language learning theories discussed in class.

In addition to the four field reports, I compiled after each class meeting detailed notes taken during class on key ideas discussed, major questions, personal stories and practical concerns. These notes depicted many significant moments in class, especially when candidates tried to relate theory and site experience.

The 10-page final project report by the candidates described the nature of their fieldwork and their learning in terms of language learning, language teaching, teaching the subject area and understanding of themselves as future teachers. Candidates also shared a one-page hand-out during their final presentation, highlighting a compelling moment of their learning during servicelearning.

As researcher, I visited many organisations in person to discuss project objectives, timelines and tutoring needs. During the project, I constantly monitored candidate progress by regularly communicating with the organisations. Feedback via email, phone and site visits was documented. The organisations also filled out an end-of-project questionnaire which contained both quantitative and qualitative information about candidates' performance, professionalism and areas for improvement, as well as the effectiveness of SLD.

\section{Data Analysis}

Data analysis of candidates' linguistic knowledge and languagerelated experience was an inductive process (Emerson, Fretz \& Shaw 1995). Data was first organised by candidate name, by site, and in chronological order. After reading the whole data set multiple times, initial coding categories were developed according to language, teaching, ELLs and the teacher's professional disposition. The language category included such subcategories as linguistic and sociolinguistic features of tutees' first language (L1) and second language (L2), L1's similarities with and differences from English, types of errors in writing, characteristics of spoken language, comprehensible input, and affective filter. Candidate observations of the difficulties and triumphs their tutees experienced throughout the project were also under this category. The teaching category consisted of interactions with ELLs, sheltered instruction, learning styles, and motivation. The disposition category covered critical discussions on tracking, immigrant education, stereotyping, language shock, teacher attitude, servicelearning, and understanding of the ELL community. The last category - ELLs - contained teaching content versus teaching English, language demands for adult and adolescent learners, and teaching academic language.

Guided by a sociocultural perspective on learning, a tutoring event was adopted as a unit of analysis. A tutoring event is defined as a social activity where tutors and their tutees participate in making sense of L1 and L2 together. Using this definition, the 
second round of analysis identified tutoring events in the whole data set. Twenty-five events repeatedly mentioned by candidates and 18 that addressed similar issues (for example, student writing) were selected for closer examination and triangulation with all data sources. Using tutoring events, the initial coding categories, including the subcategories, were re-examined and re-grouped to highlight candidates' experiences. Two examples illustrate this re-grouping. First, in 24 out of the 25 events, candidates focused on tutees' written rather than their spoken language. From this data, the spoken language event was omitted because it was not representative of candidates' discussions. The other example was that of a candidate teaching English songs in a migrant worker centre. The data was originally in the subcategory of 'affective filter' under the language category, but was subsequently included in the teaching category because the candidate analysed her use of songs as a strategy rather than as the learning of songs and lyrics.

Final coding was developed around (a) candidates' knowledge of L1 and L2 development (for example, communicative competence, pronunciation, and writing) and the kind of instructional decisions that responded to this knowledge (for example, teaching vocabulary, writing, foreign language teaching methods, creating opportunity for expression, and assessing learning styles); and (b) candidates' situated learning in a community where they learnt from and with peers and ELLs.

\section{FINDINGS}

Despite their expertise in various subject areas, all candidates became students of language through observing and participating in service-learning. Given limited credit hours for the course and the vast amount of information needed, the candidates focused on individual ELLs in their inquiry into language learning in the community. The mutually beneficial relationships among members of the community encouraged candidates' thoughtful, critical reflections on the nature and meaning of learning a second language in contexts.

\section{'Sofa', 'Amirca' and 'Bike': (Re)constructing Sociolinguistic Knowledge in Contexts}

This section describes how the candidates developed and reflected on their curiosity and awareness of the sociolinguistic features of the English language together with the ELLs' home languages during their tutoring experience. (Note that all names are fictitious.)

As an assistant to an ESL teacher in a beginning-level adult class, Wilson worked closely with students in small group settings. A vignette in his field report reflected a common theme in all candidates' work, namely, to rethink linguistic knowledge beyond worksheets and vocabulary lists: 
a more authentic situation. I told $H$ [who is from Yemen] and her circle that I wanted to visit their home in Yemen. Funniest was when I complimented the hostess $(H)$ on the lovely sofa. She asked what a 'sofa' was. 'We don't have sofas in Yemen.' She then attempted to explain in English the kind of seating I could expect if I visited a Yemeni home (even in the U.S.). I never thought I'd be teaching an ELL student the word 'sectional' (to denote couches joined together in a ' $U$ ' shape). It was esoteric and, at the same time, marvelously fun (Wilson, field report).

For Emily, teaching the differences between the two phrases 'Excuse me' and 'Excuse me?' reminded her of the 'importance of knowing the different melodies of spoken words in any language and the importance of contexts in language learning and teaching'. Emily explains her approach:

I wanted to be sure to communicate that the phrase 'Excuse me?' is applicable to multiple situations, and that tone and melody have everything to do with that communication. So I acted out ... I bumped into someone's desk and said, 'Oh, excuse me.' Then, I asked a student to speak to me in their home language, listened for a moment, scrunched up my face in confusion and said, 'Excuse me? I don't understand' (Emily, final report).

Like Wilson and Emily, many candidates emphasised the importance for teachers to understand the notion that language is a social tool with which students explore when and where to say what to whom. This is because, as Yolanda writes, 'when they have social utility and purpose for the learner, then learning is enhanced and actually empowers the learner' (Yolanda, final report).

Tutees' home languages and their impact on their learning of English were also explored. In their service-learning sites, candidates were exposed to Arabic, Spanish, Chinese, Tagalog, Russian, Farsi, Thai, Vietnamese, Burmese, and their numerous regional dialects, which mirrored the linguistic reality in California. Many candidates agreed that working with their tutees had stimulated more curiosity (rather than insecurity and embarrassment in being monolingual) about and daring exploration of their students' home languages, which mediated their understanding that all languages are symbolic tools for expression, and that students were drawing upon their language resources to communicate. For example, Julia recorded her observation of her Jordanian tutee, A:

A wrote a touching story about his childhood. Although his papers show some common errors that are likely related to his primary language of Arabic, they do not interfere with my understanding of his stories (Julia, final report).

Nina, who worked with a Muslim girl, K, from Saudi Arabia, noted that teachers should understand why learners made such errors: 
For example, in the word 'Amirca' (Ah-mer-ri-ca) that $K$ wrote, the important vowel sounds are the long ones, Ah, mer, and ca. 'Ri' has a short vowel sound, and in Arabic one would not write a letter for the $i$ (Nina, final report).

Candidates also quickly realised that language registers differently in various social settings - in particular, daily communication versus academic discourse. For example, Fynn met two Korean tutees who understood the daily announcements played on the intercom system, but had trouble reading directions in maths homework. Larry offered an analogy to remind himself to integrate language in content and context:

The definition for bicycle reads, 'a vehicle consisting of a light frame mounted on two wire-spoked wheels one behind the other and having a seat, handlebars for steering, brakes, and two pedals or a small motor by which it is driven'. If one were unfamiliar with a bicycle, how helpful would that definition really be? (Larry, field report).

Inspired by the tutees' fascinating language diversity, candidates' curiosity about their tutees' home languages and their willingness to investigate linguistic and sociolinguistic features of their first language (English) more thoroughly became one major milestone in their learning.

\section{A Student of Language: Learning in a Community with Mutual Benefits}

Hallman and Burdick (2011, p. 354) argue that 'because the service-learning environment required close relationships through one-on-one tutoring, pre-service teachers were not positioned in a traditional teacher role, standing in front of a (passive) class and extolling information'. This section discusses how the mutually beneficial relationships built in the tutee project community strengthened candidates' learning with and from all members of the service-learning community, including their tutees, peers and supervising teachers on site.

Candidates experienced an emotional shift from insecurity to confidence from working closely with their tutees. Their shock and feelings of incompetence during the earlier stages of the project were evident in all 28 field reports and class discussions. When Keith realised he would be stepping into a room with 30 ELLs, he was 'completely sure that [he] would not only fail, but do so in a tremendous fashion (Keith, final report)'. The struggle for 10 candidates who were bilingual or multilingual lay in negotiating multiple languages in teaching. For example, Nicole asked how to help her immigrant students to make meaning in English using their resources in Chinese.

The service-learning tutee project offered a mutually beneficial platform for all participants, especially the candidates. First of all, given its one-on-one setting, the tutors learned to communicate with their tutees more effectively, by using a combination of English, body language and visual scaffolds 
to build sociolinguistic and pedagogical knowledge and skills. For example, Anna realised that the grammar pattern drills confined her students' need to express themselves. Larry 'witnessed [his tutee] experience both highs (receiving an ' $\mathrm{A}$ ' in Science) and lows (constantly being made fun of because of his Mexican ancestry)', which impacted his tutee's learning (Larry, field report). In their reflections, many candidates like Anna and Larry emphasised how their tutees taught them the importance of investigating the learning environment, and of investing 'a great deal of vision, commitment, tenacity, patience and openness' in teaching (Nadya, presentation).

Second, candidates gained experience and confidence in collaborating with peers and colleagues. John and five other candidates teamed up with Ms Chung, an experienced teacher who supervised the group, to work with a group of beginner-level adults. In addition to group planning, as a group they wrote a teaching journal detailing specific growth, areas for improvement and such grouping strategies as 'wife translating for husband' (team journal). The journal also contained the kinds of interactions to which the tutees responded well, such as reviews, jokes, repeated pronunciations and games. Ms Chung met with the candidates regularly. She encouraged the candidates to take cues from their tutees. John's team used their journal to document the tutees' daily progress and the trial and error of the team.

On-site teachers like Ms Chung and agency administrators were crucial mentors for candidates. They promoted effective teaching and critical thinking by welcoming them to their classrooms/programs. As Yolanda recorded, she enjoyed watching her mentor teaching English and admitted that, 'no college course could have provided me with the range of methodologies that this [ESL] instructor used over the several weeks that I worked with him'. Several candidates in a Vietnamese youth centre were invited to join their immigrant students in a protest against the state's budgetary cut in public education. Stacey and Holly led a discussion among 17 immigrant students on social justice and activism before the protest. Their tutees learned to produce posters and slogans. As Stacey wrote, 'We are proud that we helped the students gain a voice using English. We are grateful that the Center and the students gave us the opportunity to link current affairs to teaching English' (Stacey, field report).

The local immigrant agencies benefited from regular assistance throughout the semester to the immigrant populations they served. Based on their evaluation of candidates' participation and the impact of this tutee project, the agencies reported progress and milestones. For instance, an adult education unit appreciated the fact that the candidate team taught an unprecedentedly large group of Yemeni refugees. Several after-school tutoring sites praised their efforts in going beyond ordinary homework assignments. A centre for migrant workers celebrated a well-received music-based literacy course planned and taught by one candidate. The tutees expressed their gratitude in their homework, class projects or after 
tutoring sessions, which was 'quite a humbling experience' for the candidates because, as Jonathan wrote, 'I am just a teacher in training' (Jonathan, field report).

The teacher candidates also benefited. They were offered challenging, realistic classroom scenarios that forced them to make connections between their developing knowledge of languages and their tutees' ongoing struggles, between second language development theories and pedagogical implications. The on-site collaborating teachers and staff reciprocated the support by clearly communicating their goals and methods throughout the project, accommodating the candidates' scheduling needs, constantly supervising progress and by responding to the instructor's communication in a timely manner. Most importantly, the tutees were regarded by the candidates as excellent teachers in their own right, inasmuch as they opened up to their tutors and demonstrated how rewarding and challenging learning a second language could be for different individuals. The candidates became their students and learned tremendously from this community of learners.

\section{DISCUSSION}

Building sociolinguistic knowledge from the sociocultural experiences of working together with ELLs is key to candidate preparation for language diversity in their future classrooms. It is encouraging to notice that candidates in this study started to develop deep insights about language, learning and immigrant experiences. They also learned to explore sociolinguistic and sociocultural concepts in second language literacy. In addition, as both language learners and language teachers who benefited, and were benefited by, their project partners, they built their knowledge and experience together with those partners 'through contact, collaboration, and community' (García et al. 2010, p. 132).

\section{Developing Language Skills}

While immersing themselves in immigrant communities with ELLs, candidates had opportunities to accumulate what Lucas and Grinberg (2008) assessed as language-related knowledge, experiences and skills teachers need for teaching ELLs. The anecdotes of 'sofa' and 'Amirca', as well as the 'bike' analogy, suggested opportunities for candidates to 'conduct basic linguistic analysis of [ELL's] oral and written text' and to participate 'in cross-cultural and cross-linguistic communication' (Lucas \& Grinberg 2008, p. 611).

In their reflections and field reports, candidates discussed the sociolinguistic demands of oral and written language for specific language lessons and for their students' schoolwork, compared ways people use languages in their cultures, and explored instructional techniques that promote understanding and mastery of English. At the same time, they compared different forms, usages and structures in ELLs' home languages (L1) and concluded that language errors ELLs make should not be viewed as evidence 
of an ability deficit in the learner, but as a complex process which should be understood in context and with a knowledge of the home language (for example, Hansen 2010). This initial pursuit of language development served as a springboard for more in-depth studies of the social dimensions of language.

The service-learning pedagogy offered candidates authentic literacy cases to investigate; furthermore, the variety of such sociolinguistic inquiries offered the whole group even more information about, and exposure to, different cultural traditions in language practice and language learning. Teacher candidates could apply their analyses of their field experience to their classroom teaching, where they need to articulate the academic language demands of their subject matter. Overall, the candidates reported a better sense and direction of what to focus on and how to make the language and content explicit and relevant to their students.

\section{Building a Community of Mutual Benefits}

While building their sociolinguistic knowledge and skills, teacher candidates developed the multiple identities pertinent to various aspects of their profession. All participating candidates experienced identity shifts from mainstream English speaker to helpless language teacher, from confident content teacher to anxious student of languages. Such new learning environments and contexts had a profound impact on 'where [the candidates] place their effort, whether and how they seek out professional development opportunities, and what obligations they see as intrinsic to their role' (Hammerness, Darling-Hammond \& Bransford 2005, p. 384). The premise of this study was that learning to teach is a social practice situated in the daily dynamics of a community. Candidates developed their sociolinguistic and pedagogical knowledge from their tutees and collaborating teachers while working with them, indicating that the social roles of participants change as the social practice itself is in motion (Lave \& Wenger 1991).

In addition, the service-learning tutee project made the learning experience reciprocally fruitful. 'Reciprocity suggests that every individual, organization, and entity involved in the servicelearning functions as both a teacher and a learner. Participants are perceived as colleagues, not as servers and clients' (Jacoby 1996, p. 36). Candidates' on-site team teaching journals, discussed previously, reflected how teaching and learning intertwined and supported each other. The underlying principle of such practice is a community-oriented view of teacher learning that is 'marked by mutual engagement, joint enterprise, and shared repertoire' (BoyleBaise \& McIntyre 2008, p. 319).

In order to make such community-based service-learning projects more sustainable, it is important to recognise the institutional constraints (for example, Walker, Ranney \& Fortune 2005) and research needs of longitudinal studies. First, SLD is offered in the second of a two-semester program, when candidates 
also student-teach two levels or grades of classes in their subject area, take two more credential courses and complete a high-stake teaching performance assessment (Performance Assessment for California Teachers, or PACT). All participants in this case study agreed that moving SLD to the first semester would be much more beneficial to all parties involved. Second, the limitation of this study is that it lasted only a semester; therefore, studies that follow the service-learning participants further into their teaching careers to provide information about impacts on their future practice are desirable.

\section{CONCLUSION}

Language is a social tool for communication. It is through the sociocultural practices of using this tool that we best understand the meaning and complexity of the learning and teaching of language. What teacher educators can do in an SLD course is to make sure that the curriculum, to quote author Anne Haas Dyson, is 'permeable' in order to include a variety of case studies with ELLs, so that discussions of theories and practices (see Gebhard 2010 , on the use of systemic functional linguistics in teacher preparation) are grounded in and guided by specific social, linguistic and political aspects of second language learning that teachers encounter in their schools and communities. Through community-based service-learning, teacher candidates can build their language-related knowledge and skills on a spectrum of case studies that address the overall phenomenon of second language learning. Methodologically, they can carry out small-scale case studies of second language development in their fieldwork, which requires them to identify language-related problems, refer to theoretical interpretations that may help clarify them and experiment with relevant strategies to solve them. In so doing, candidates not only learn to make educated decisions on building students' academic literacy, but also develop habits of inquiry in fieldwork. It is crucial that they understand that, no matter how many strategies they have accumulated for teaching language, they should concentrate on the cues from their ELL students for the best ways to support language development.

In addition to an inquiry-based methodology, the positive outcomes of the tutee project suggest that teacher educators should thoroughly understand service-learning as a pedagogy. We cannot assume that mutual benefits to all participants will be automatically present; neither can we ignore the tensions created by a hegemonic model that assumes that the tutees beg for knowledge and skills from the tutors (Hellebrandt 2006). Consequently, 'instructors must make a special effort to articulate and align students' capabilities and the community partners' needs in three areas: language proficiency, cultural knowledge, and professional skills' (Lear \& Abbott 2009, p. 312). Teacher educators should promote the importance of understanding students' lives. Language is a social act; therefore, in order to 
support ELLs' language development, candidates should be given guidance on how language use is infused in daily living, how life stories inform the ways people learn language, and ultimately on how to incorporate their experiences and stories into curriculum, planning and instruction (Weinstein 2006).

This study offers local instructional experiences and theories (Morris \& Hiebert 2011) for teachers and teacher educators to develop sociolinguistic and pedagogical tools while supporting and being supported by the ELL communities. This experience provided participating candidates with new inspiration and new ways to reflect on learning and teaching language in their future subject area classrooms, because becoming linguistically responsive (Lucas, Villegas \& Freedson-Gonzalez 2008) is a basic and yet much needed quality for all classroom teachers.

\section{ACKNOWLEDGEMENTS}

I thank the anonymous reviewers and Managing Editor of Gateways Margaret Malone for their insightful comments. The development and implementation of the service-learning project described in this article were funded by a Community Scholarship Faculty Grant from the Institute for Civic and Community Engagement of San Francisco State University.

\section{REFERENCES}

Ballantyne, K, Sanderman, A \& Levy, J 2008, Educating English language learners: Building teacher capacity, National Clearinghouse for English Language Acquisition, Washington, DC.

Blum, D \& de la Piedra, T 2010, 'Counter-storytelling through servicelearning: Future teachers of immigrant students in Texas and California re-tell the "Self" and the "Other", International Journal of Progressive Education, vol. 6, no. 2, pp. 6-26.

Boyle-Baise, M \& McIntyre, D 2008, 'What kind of experience? Preparing teachers in PDS or community settings', in M Cochran-Smith, S FeimanNemser \& D McIntyre (eds), Handbook of research on teacher education: Enduring questions in changing contexts, Routledge, New York, pp. 307-30.

Emerson, R, Fretz, R \& Shaw, L 1995, Writing ethnographic fieldnotes, University of Chicago Press, Chicago, IL.

Fan, Y 2009, 'Lost in institution: Learning to write in Midwestern urban mainstream classrooms', Journal of Southeast Asian American Education \& Advancement, vol. 4, pp. 1-17.

Friedman, A 2002, 'What we would have liked to know: Preservice teachers' perspectives on effective teacher preparation', in A Beykont (ed.), The power of culture: Teaching across language difference, Harvard Education, Cambridge, MA, pp. 193-217.

García, E, Arias, M, Murri, N \& Serna, C 2010, 'Developing responsive teachers: A challenge for a demographic reality', Journal of Teacher Education, vol. 61, nos 1-2, pp. 132-42.

Gebhard, M 2010, 'Teacher education in changing times: A systemic functional linguistics (SFL) perspective', TESOL Quarterly, vol. 44, no. 4, pp. 797-803. 
Hadjioannou, X \& Hutchinson, M 2010, 'Putting the G back in English: Preparing pre-service teachers to teach grammar', English Teaching: Practice and Critique, vol. 9, no. 3, pp. 90-105.

Hale, A 2008, 'Service learning with Latino communities: Effects on preservice teachers', Journal of Hispanic Higher Education, vol. 7, no. 1, pp. 54-69.

Hallman, H \& Burdick, M 2011, 'Service learning and the preparation of English teachers', English Education, vol. 43, pp. 341-68.

Hammerness, K, Darling-Hammond, L \& Bransford, J 2005, 'How teachers learn and develop', in L Darling-Hammond \& J Bransford (eds), Preparing teachers for a changing world: What teachers should learn and be able to do, Jossey-Bass, San Francisco, CA, pp. 358-89.

Hansen, G 2010, 'Word recognition in Arabic as a foreign language', The Modern Language Journal, vol. 94, no. 4, pp. 567-81.

Hart, S \& King, J 2007, 'Service learning and literacy tutoring: Academic impact on pre-service teachers', Teaching and Teacher Education, vol. 23, no. 4 , pp. 323-38.

Hellebrandt, J 2006, 'Spanish service-learning research from 1999-2003: Effects on faculty, department, community, and discipline', Hispania, vol. 89 , no. 4 , pp. 919-26.

Henry, S, \& Breyfogle, M 2006, "Toward a new framework of "server" and "served": De(and re)constructing reciprocity in service-learning pedagogy', International Journal of Teaching and Learning in Higher Education, vol. 18 , no. 1 , pp. $27-35$.

Hollins, E \& Guzman, M 2005, 'Research on preparing teachers for diverse populations', in M Cochran-Smith \& K Zeichner (eds), Studying teacher education: The report of the AERA Panel on research and teacher education, Lawrence Erlbaum, Mahwah, NJ, pp. 477-548.

Howard, J 2001, Service-learning course design workbook, OCSL Press, Ann Arbor, MI.

Jacoby, B 1996, Service-learning in higher education, Jossey-Bass, San Francisco, CA.

Lave, J \& Wenger, E 1991, Situated learning: Legitimate peripheral participation, Cambridge University Press, Cambridge, MA.

Lear, D \& Abbott, A 2009, 'Aligning expectations for mutually beneficial community service learning: The case of Spanish language proficiency, cultural knowledge, and professional skills', Hispania, vol. 92, no. 2, pp. 312-23.

Lucas, T \& Grinberg, J 2008, 'Responding to the linguistic reality of mainstream classrooms: Preparing all teachers to teach English language learners', in M Cochran-Smith, S Feiman-Nemser \& D McIntyre (eds), Handbook of research on teacher education, Routledge, New York, pp. 606-36.

Lucas, T, Villegas, A \& Freedson-Gonzalez, M 2008, 'Linguistically responsive teacher education: Preparing classroom teachers to teach English language learners', Journal of Teacher Education, vol. 59, no. 4, pp. 361-73.

Morris, A \& Hiebert, J 2011, 'Creating shared instructional products: An alternative approach to improving teaching', Educational Researcher, vol. 40, no. 1, pp. 5-14.

Ponder, J, Veldt, M \& Lewis-Ferrell, G 2011, 'Citizenship, curriculum, and critical thinking beyond the four walls of the classroom: Linking the 
academic content with service-learning', Teacher Education Quarterly, vol. 38 , no. 4 , pp. 45-68.

Spencer, B, Cox-Petersen, A \& Crawford, T 2005, 'Assessing the impact of service-learning on preservice teachers in an after-school program', Teacher Education Quarterly, vol. 32, pp. 119-35.

Stanton, T \& Erasmus, M 2013, 'Inside out, outside in: A comparative analysis of service-learning's development in the United States and South Africa', Journal of Higher Education Outreach and Engagement, vol. 17, no. 1, pp. 61-94.

Szente, J 2008, 'Preparing preservice teachers to work with culturally and linguistically diverse children: A service learning experience', Journal of Early Childhood Teacher Education, vol. 29, no. 2, pp. 140-45.

Valdés, G 2001, Learning and not learning English: Latino students in American schools, Teachers College Press, New York, NY.

Walker, C, Ranney, S \& Fortune, T 2005, 'Preparing preservice teachers for English language learners: A content-based approach', in D Tedick (ed.), Second language teacher education: International perspectives, Lawrence Erlbaum, Mahwah, NJ, pp. 313-33.

Weinstein, G 2006, “Learners' lives as curriculum”: An integrative project-based model for language learning', in G Beckett \& P Miller (eds), Project-based second and foreign language education: Past, present, and future, Information Age Publishing, Charlotte, NC, pp. 159-66.

Wong, P 2008, 'Transactions, transformation, and transcendence: Multicultural service-learning experience of preservice teachers', Multicultural Education, vol. 16, pp. 31-36. 